\title{
Prevention of burn-out
}

\section{Glenn A. Roberts}

There is a widespread concern that the medical profession is itself sick. This is represented in professional disillusionment and demoralisation, an increasing inclination to consider leaving the profession, and the ill-health of its practitioners in terms of their mental health, marriages and use of drugs and alcohol (British Medical Association, 1992). These trends have been attributed, at least in part, to protracted job stress and dissatisfaction, which may in turn be a major determinant in the quality of health care (Caplan, 1994). Although these issues have been cautiously acknowledged for some time, the concept of 'burn-out' has provided an opportunity for more open acceptance and creative debate.

When Freudenberger (1974) coined the term 'burn-out' to describe the demoralisation, disillusionment and exhaustion he observed in mental health workers, he inaugurated a new model for considering work-related distress and dysfunction. This has proven to be accessible and acceptable to doctors and many other health care professionals. It has focused on a pathology of professionalism and served as a means of breaking through the taboo that doctors commonly feel in speaking to each other about their inner lives, personal struggles and vulnerabilities. There are established models to account for low self-esteem, stress, anxiety and depression in our patients but doctors have been reluctant to apply these to themselves. The clustering of observations and ideas around burn-out has enabled members of the caring professions to explore their career development and training and consider the covert agendas that motivate their work for healing, which may set them up at a later stage to mismanage professional relationships, roles and stresses.

Burn-out is not a scholarly construct but an evocative and imprecise metaphor. Although it has now been graced with diagnostic status (ICD-10: Z73 - Problems related to life-management difficulty), it is undoubtedly a new name for an old problem. It may be best conceptualised as a 'fuzzy set' (Burisch, 1993), a generic name for the results of prolonged job stress and certain kinds of occupational crisis. Although recent work has demonstrated that burn-out can be distinguished from other forms of stress, both conceptually and empirically, and it is therefore not just a 'flabby' synonym for more established symptomatic states, there remains a need to underpin an integrated and comprehensive model with systematic research (Burke \& Richardsen, 1996).

Prevention can only follow acknowledgement and understanding. I will adopt a practical and personal approach: first describing a model and definition of burn-out and then exploring changes that are commonly associated with prolonged or excessive occupational stress. I will review some established causes and then discuss a range of suggestions for intervention and prevention. The evidence that underpins a discussion of burn-out is not so much epidemiological or experimental as the manifest popularity and utility of the concept and the accumulated observations of experienced professionals.

The significance of this topic was brought into sharp focus for me when I travelled to a rural area to give a talk on burn-out to the local general practitioners. On my arrival I discovered that the organiser of the vocational training scheme had shot himself dead a few weeks before. He was described as an exemplary doctor who seemed to epitomise the principles of hard work, high standards and dedication to his profession. Nobody appeared to have been close to him personally nor known what was happening to him. The group I met with were shocked and perplexed - what had gone wrong?

Glenn Anthony Roberts is a consultant in general adult psychiatry and drug addiction at North Devon District Hospital, Raleigh Park, Barnstaple, Devon EX31 4JB. He has a long-standing interest in the problems of chronic psychotic illness and quality of life in schizophrenia and has conducted many seminars and workshops for doctors on burn-out, including an annual residential retreat for general practitioners. 
He appeared to illustrate the striking conclusion of the King et al (1992) survey of emotional distress in doctors:

Doctors working in the health service are subject to high levels of personal distress ... they have difficulty disclosing this to anyone outside their immediate family and friends ... The ethos of the medical profession is to deny health problems.

There is obvious concern for the morbidity of medical practice for practitioners but also, given that their health is vital to the safety and quality of patient care, there must be grave concern that:

Doctors' health problems are poorly dealt with, interventions come too late, and appreciable attitudinal and organisational barriers exist to the take up of services (Donaldson, 1994).

Psychiatrists are often looked to for help in treating these doctors or in providing a response to the occupational stress of colleagues (Fawzy et al, 1983) and therefore have a particular need to first look after themselves and put their own house in order.

\section{The concept of burn-out}

The burn-out literature is unusual in that the majority of the 2500 articles and books written since 1974 are anecdotal, written by practitioners rather than academics. There is a modest amount of what could be recognised as research and a great deal of speculation and practical suggestions. It is something of a folk literature, an accumulated wisdom, partly supported by correlation studies. The development of the Maslach Burn-Out Inventory (MBI; Maslach \& Jackson, 1986) and the Tedium Scale (Pines et al, 1981) have provided psychometric tools to enable a more standardised approach.

Some authors (King, 1993) have deprecated the term 'burn-out' for its imprecision and overlap with related concepts such as post-traumatic stress disorder, depression and boredom, or have regarded it as faddish psychobabble (Morrow, 1981). Others have made links with existing models such as general stress theory (Hobfoll \& Freedy, 1993), learned helplessness (Meier, 1983) and the psychodynamics of helplessness in the helpers (Adler, 1972), Bandura's model of self-efficacy and competence (Cherniss, 1993) and with the compulsive care-giving of the 'helping profession syndrome' (Malan, 1979). In terms of Selye's (1956) definition of the stress process (i.e. alarm, resistance and exhaustion), burn-out may be likened to the third stage and is preceded by unmanageable and sustained levels of arousal.
Burn-out is not an event but the end point in a process of 'burning down'. We work in challenging and turbulent environments, in which the only certainty is that there will be constant change. Stress is caused by a multitude of demands (stressors). Stressors add up over time and across the compartments of our lives. Our sense of control over what is happening may be critical. If we learn to respond adaptively, we are increasingly able to be effective and enhance our capacity and confidence, whereas maladaptive responses lead us in a downwards spiral towards burn-out. When demands (internal and external) persistently outweigh resources (internal and external), an individual becomes unbalanced. A sustained or progressive disequilibrium eventually leads to burn-out. Burn-out is not the result of stress but of mismanaged stress.

\section{Recognition of burn-out}

Often, individuals who are burning down or burning out have great difficulty recognising this, and resistance increases with severity. It may help to use some objective inventory (Haslam, 1994; Chambers, 1995), and recognition is undoubtedly easier in an occupational setting that does not regard stress as a moral flaw and react pejoratively to those suffering from it.

Maslach \& Jackson (1986) divide the features of burn-out into three clusters: emotional exhaustion, depersonalisation and reduced personal accomplishment, which may be experienced or expressed in many ways (Box 1). Although these run the risk of appearing as a long 'laundry list' of signs and symptoms, they collectively represent a transition, whereby those we are seeking to help become a threat to the practitioner and the practitioner becomes preoccupied with his own needs and survival. Many symptoms of burn-out correspond to maladaptive coping strategies which aim to keep the patient at a distance; these may work in the short term but without resolving anything and therefore compounding the burn-out process. Schwartz \& Will (1953) gave an early description of the tendency to mutual withdrawal between demoralised staff and patients which, once established, became self-reinforcing.

\section{Origins of burn-out}

There is a regrettable tendency for employers and peers immediately to attribute responsibility for 
Box 1. Signs and symptoms of burn-out

Changes in behaviour-frequent clock-watching; increasing resistance to going to work; postponing contact with patients; often late (run late and leave late); loss of creative problem-solving ability; working harder and later but achieving less; withdrawal and avoidance of colleagues; stealing from the organisation; increasing use of mood-altering drugs (including caffeine and nicotine); inability to pursue recreational and recovery needs; and accident proneness.

Changes in feelings - loss of humour or gallows humour; persistent sense of failure, guilt and self blame; frequent anger, resentment and bitterness; increased irritability, expressed at work and home; feeling under attack; feeling discouraged and indifferent; powerlessness; and coping rather than creating.

Changes in thinking-increasing thoughts of leaving the job; inability to concentrate; rigid thinking, resisting change; increasing suspiciousness and distrust; cynical, blaming attitude towards patients; de-humanising attitude to patients; victim mentality; and preoccupation with one's own needs and personal survival.

Changes in health-disordered sleep; frequent long-lasting minor ailments; increased susceptibility to infections; weariness - tired and exhausted all day; and precipitation of physical and mental health problems.

burn-out to the individual. However, many important stress variables impinge on the occupational role before a specific individual is even appointed. Burn-out is the end result of a complex equation (Firth-Cozens, 1994), which may include the context in which we work, and educational, organisational and personal factors. Few of the suggested mechanisms have any empirical evidence to support them. They stand as a catalogue of hypotheses to stimulate further reflection and enquiry, and point towards different levels of intervention.

The culture and context in which we practice has been subject to increasing recessionary and fragmentary processes common to society as a whole. Patients have less access to community and family resources and produce a greater demand for professional involvement, with a higher expectation for care and change. At the same time these professionals have come under increasing public scrutiny. Overall, there appears to be a general progression towards expecting more and more, while resources diminish. Health care professionals are in danger of being progressively disempowered while being held increasingly accountable. Furthermore, the imposition of a naive business culture which describes staff as 'anonymous units of production' (Lancet, 1994) and wards as 'income generation units', disenfranchises those who are personally committed to their work.
These cultural changes may be reflected in an attitude shift in our junior colleagues. There may be a trend towards regarding medicine not so much as a vocation, than as a job, which may lead to conflict and dissonance with trainers who expect (or at least hope for) a level of commitment that trainees now consider inappropriate. Senior doctors may also project their lost ideals into their juniors and then attack them for failing to fulfil them. Doctors are increasingly unwilling to accept what some feel are 'outmoded and punitive' career systems (Policy Studies Institute, 1994). There appears to be a progressive loss of doctors from the profession; it has been reported that 15 years after they have qualified a quarter of doctors have ceased to practice (Hospital Doctor, 1995). There are now many studies that document widespread dissatisfaction and regret at choosing a career in medicine (Allen, 1988, 1992, 1993).

The Faculty and Society of Occupational Medicine (MacDonald \& McCloy, 1994) recently commented that 'finding a senior doctor who wants to work until normal retirement age is difficult now'.

\section{Educational factors}

Successive revisions of the educational process, examinations and academic expectations have 
been justifiably credited with a progressive rise in standards, yet our educational system appears to prepare us poorly for the realities of medical practice, and fails to sustain our commitment, morale, health and enthusiasm. It may, in part, be that we continue to neglect the person of the doctor. We are taught a lot about the theory and practice of medicine but little about how to look after ourselves and cope with the inevitable stresses (Grainger, 1994). Teachers who are detached from the reality of clinical work tend to suggest that all problems have solutions and fail to prepare trainees for inevitable frustrations and uncertainties ('reality shock'). They are thus inducted into idealistic rather than realistic models, which are ultimately unworkable. The ancient image of the 'wounded healer' contrasts with the 'macho medic' or the business-trained practitioner. There may be a covert message that stress equals weakness, failure and inadequacy, which promotes shame-based denial or concealment and mitigates against owning, sharing and resolving.

\section{Occupational factors}

The notion that 'if you cannot stand the heat get out of the kitchen' is tragically misplaced and diverts attention from 'kitchens' that are dangerously neglectful of the health of those working in them. The British Medical Association's (1992) review of stress and the medical profession concluded that the National Health Service had in many respects "notably failed to provide a safe and supportive environment for its staff". The highly publicised and successful actions by $\mathrm{Dr}$ Chris Johnstone (Hospital Doctor, 1995) and social worker John Walker (Unison, 1995), after suffering depressive breakdowns attributed to work stress, may help to focus attention on the responsibility of employers.

It has long been recognised that working with certain groups of patients is additionally stressful: the elderly, chronically or terminally ill, patients requiring intensive care, neonates, the mentally ill, drug misusers and patients with aggressive and threatening behaviour. Burnout is considered pre-eminently a disorder of the over-committed and thwarted, and collectively these patients share a number of characteristics that tend to attract committed idealists; some are less responsive in terms of clear and simple outcomes and as such confront us with our impotence and the limits of our capacity to stay with enduring suffering; others are excessively susceptible to our mistakes, while yet others breach our boundaries.
Pines \& Maslach (1978) found that the longer staff had worked in mental health settings the less they liked working with patients, the less successful they felt with them and the less humanistic were their attitudes to mental illness.

There is a consistent association between burnout and occupational roles which are compromised and unsupported, leading to overload, ambiguity or conflict (Burke \& Richardsen, 1996). This triad describes many unmanaged multi-disciplinary teams.

Leadership styles that consist of giving only negative feedback ('I'll tell you if you've done it wrong') have been associated with high burn-out, in contrast with a style which offers positive feedback and supports autonomy (Duxbury et al, 1984). There is an important parallel with attachment processes in family life and professional practice which foster the development of confidence and competence and emotional security (Richman \& Flaherty, 1985). Burnout is also contagious, and stressed bosses provide a negative model for their trainees.

\section{Personal factors}

Much is set in place that will enhance or disable an individual's performance before they take up a post. There may also be personal factors which may render the individual more vulnerable.

The stress-prone (type A), driven, 'stress-junkie' personality is a well-recognised stereotype, but interestingly one model of the burn-out process (Edelwich \& Brodsky, 1980) has 'idealistic enthusiasm' as its first stage. It is broadly accepted that it is the caring and the committed who are most vulnerable; as the saying goes, 'you have to be on fire to burn-out', and therefore some of the most effective and productive are at greatest risk. They tend to have idealistic rather than realistic expectations, become over-involved and have difficulty in detaching. They may be co-dependent and have a strong need to be needed, valued, appreciated and accepted (Vincent, 1983) and are more susceptible to the seductions of occupying the 'virtuoso role' (Bennet, 1987). They tend to lose touch with ordinary social contacts and personal relationships in which they can express their need and vulnerability, and so come to live in a small world where many or most of their gratifications are derived from their occupational role or the institution for which they work. Their existential needs come to be met through their professional identity and so occupational threats and stresses are experienced as challenging fundamental hopes, goals, meaning and purpose (Pines, 1993) and there is little to offset this in collateral support. 
Many doctors have no-one other than their spouse or partner to talk to about anything personal. In doing so they risk contaminating their personal relationships by importing occupational issues into the home and being unavailable to fulfil and enjoy their other responsibilities. The image of the doctor-parent who is unable to detach from work and is unavailable for his or her children remains a tragic stereotype.

The greatest regret expressed by most physicians I have known or seen professionally is that they relegated to secondary importance the satisfactions in living that stem from the quality of the physician's relationship with his or her spouse and the children (Schwab, 1995).

\section{Prevention of burn-out}

Prevention begins with recognition and understanding. The first step in managing burn-out is to take responsibility for your own experience of stress and then make a commitment to change. We must ensure that our own needs are met in order that we have something to give to our patients and colleagues. However, there is no consensus on what measures to take. There are no simple or universal solutions (Firth-Cozens, 1994). The important thing is to take up the challenge and gradually consider what we need and how to tailor 'stress-busting' strategies to our particular situation.

If you are in some way affected by these difficulties or seeking to help someone who is, it can seem daunting to make any changes. People affected by burn-out are exhausted and demoralised, and there may be an immediate need to create protected time and space to recover some energy before reflecting on what is causing the problems and being able to plan a response. Seek help earlier rather than late. If you are ill, do not pretend you are not, avoid self-medication and see your doctor.

It cannot be over-emphasised that attending lectures and workshops, and reading and talking about burn-out are no substitute for doing something about it. We need to become our own stress-management experts and learn to set or reset priorities and consider a change of lifestyle, building changes into our everyday routine. This can be a long, complex and sometimes costly process. The consequences of neglecting our occupational health, however, are considerable.

\section{Personal changes}

In taking responsibility for your experience of stress, you begin to take control, and in doing so mentally shift from victim to survivor. If we do not take the initiative in working out our own burnout strategy, it may be that no one else will, and nothing will change.

We can start by re-kindling the attitude that our work could be, and should be, enjoyable and renewing (Baens, 1992) and cultivate our personal resources to support us in this position. In cultivating a peer, mentor, confidante or therapist, it is essential to find someone of 'fighting weight', and to establish the relationship before it is needed, as there seems a universal tendency for doctors to withdraw under stress. Membership of a confiding and confidential group can be particularly effective in normalising stress issues and learning from them, but the ubiquitous 'staff group' seldom seems to realise this potential. Developing and sustaining creative and practical interests enlarges the small world of our professional preoccupations. Doctors can all too easily be people who 'used to ...' (paint, run, dance or play), but no longer have the time.

When asked, 'what would you like to do if you were not practising medicine?', doctors come up with an amazing range of activities and enthusiasms which for the most part have nothing to do with helping people. The challenge is not to see these as alternatives, but to make space for them to complement and invigorate our work. We need to look after ourselves, yet we frequently neglect even the most basic considerations of exercise, diet, relaxation and play. It has been my experience in running burn-out workshops for doctors that less than one in four (sometimes none) of those attending is satisfied with how they look after themselves. Those that are, tend to have an established inner discipline such as meditation or prayer.

And finally, at the end of a working day spent in the depths of people's lives, it may be helpful to develop some kind of 'decompression routine', something restorative that helps us to re-enter the rest of our lives and reduce 'negative spill' (Kirkcaldy \& Siefen, 1991) by maintaining appropriate boundaries between work and home.

\section{A shift in medical culture}

There are some signs of a general shift in society towards accepting and valuing vulnerability. The Samaritans Annual Conference in 1994 witnessed a remarkable keynote address, in which Professor 
Emmy Van Dursen Smith spoke of her own despair and near fatal hanging at an earlier stage of life and of how this contributed to her identification with patients and the motivation for her subsequent work. The 1200 delegates responded with a standing ovation. How many psychiatrists have been through times of mental distress or come from families where there has been significant suffering and still carry it with embarrassment rather than having the opportunity and encouragement to convert it into a source of wisdom?

There is a legend from the dawn of Western medicine, that the semi-divine physician Asclepius, whose teachings inspired both Hippocrates and Galen, was taught his healing arts by a centaur named Chiron who had a wound that would never heal which was both a source of continued suffering and of wisdom and authority (Bennet, 1987). We can work to assist this shift, from a medical culture built on denial of its own difficulties towards rediscovering the ancient and honourable tradition of the wounded healer (Nouwen, 1994).

\section{Educational changes}

Although the British Medical Association (1992) has recognised a need for changes at all levels of professional development, there is little evidence that basic survival skills are being valued and taught. Educational programmes could include time management, assertiveness, the use of supervision, stress awareness and relaxation and critical incident debriefing (Spitzer \& Burke, 1993).

There is an encouraging and interesting shift towards repersonalising medical training, renewing an emphasis on the development of the doctor as a person and his or her capacity to form good relationships with patients as the foundation for then using medical knowledge and technical skills (Branch et al, 1991).

Many doctors have been subjected to a 'shamebased' educational process which leaves them feeling very uneasy about realising they do not know what is going on or what to do, but it is precisely these situations that, if approached with curiosity and an investigative attitude, give us an opportunity to learn something new (Guze, 1979):

I believe that the best antidote to such poisonous thoughts and feelings (frustration, anger, cynicism, self-doubt - in the face of continued suffering and unrelieved pain), which truly pollute our professional atmosphere, is to cultivate the intellectual side of medical practice, to train ourselves so that all aspects of medicine, including its many frustrations and disappointments, become stimuli for creative, personal, intellectual effort.
There is an opportunity to use audit processes to register success, not just failures, and thereby promote awareness of our competence and capacity, as well as being realistic about our limitations.

This all presupposes that the educational process is staffed by those with an ability and enthusiasm for teaching and an awareness of the realities of the jobs they are equipping people for, and who are able to present themselves as realistic models that can be followed. This may involve somewhat more transparency concerning the struggles and vulnerabilities of the practitioner than is traditionally taught.

We may also need to recognise that at some stage individuals choose the depth at which they wish to practise, be that as a job, profession or vocation: the deeper the commitment, the greater the need will be to work on personal as well as professional maturity.

\section{Organisational changes}

Aveline (1995) has re-emphasised the need for employing authorities to consider their staff as their most valuable resource and give considerable care to retaining them. There are many suggested ways of improving the health of the structures we work in and with, to render them more effective in supporting the individual's commitment, morale and creativity.

The working team or department may benefit from developing a shared professional model or philosophy which is coherent, overt and collectively owned. This can include a clarification of lines of responsibility and an understanding of realistic goals; we need to know and agree on what business we are in and why. Those new to the job need a realistic and appropriate induction, and systems can be established to provide qualitative and quantitative, clinical and caseload supervision, with encouragement and assistance to organise personal supervision. One important aspect of continuing professional development may be as a strategy against burn-out, initiated within the profession.

There may be a need for career guidance throughout the professional life-cycle and greater flexibility to move between full- and part-time working (Allen, 1992, 1993). Associated with this is career counselling focused on setting appropriate performance standards for oneself and exploring ways of promoting effectiveness and competence (Cherniss, 1993).

Many recent studies have found a strong interest in medical staff for a dedicated counselling service 
(Humphris et al, 1994) and some psychotherapy departments have provided this to the general hospital.

At the end of all these measures it may be that the individual has done what he or she can do and the power and responsibility for change resides elsewhere in the system. There may then be a need for some kind of political action, for how else can we deal with the anger and powerlessness of being held responsible for issues and circumstances over which we have limited or negligible control? We may need to protest to survive and engage in what has been called 'ethical activism'. Chambers (1993) concluded a recent editorial with a call for "urgent, positive and effective action with a concerted plan from medical schools, Royal Colleges and the $\mathrm{BMA}^{\prime \prime}$ to address the problems of health-damaging stress in the practice of medicine.

\section{Provision of adequate support}

If stress occurs when demands exceed resources, it follows ultimately that either demands need to be modified or resources enhanced. Caplan's (1981) view that, "Individuals can tolerate exposure to high levels of stress without increased risk of mental and physical illness if they receive adequate support", is reinforced by the growing body of evidence demonstrating a strong relationship between effective social support and improved mental and physical health, which may well be mediated by the formation of secure attachments (Quick et al, 1996).

In practice, this means respecting and accepting the humanity of the doctor and living out our working lives in such a way that our needs can be met alongside those of our patients. What is more, we may be better and more effective doctors for it.

There is a paradox that the (medical) profession's ability to deny its emotions can be a strength when helping others to cope with serious illness and its weakness when coping with its own. For many years the emphasis has rested entirely on the former. Only now are doctors realising that admitting their own humanity may not be so bad after all. (Richards, 1989)

\section{References}

Adler, G. (1972) Helplessness in the helper. British Journal of Medical Psychology, 45, 315-326.

Allen, I. (1988) Doctors and their Carers. London: Policy Studies Institute.

- (1992) Part Time Working in General Practice. London: Policy Studies Institute.
- (1993) Doctors and their Careers. London: Policy Studies Institute.

Anon (1994) Burnished or burnt out: the delights and dangers of working in health. Lancet, 344, 1583-1584.

Aveline, M. (1995) Occupational stress and performance in mental health workers. Current Opinion in Psychiatry, 8, 73-75.

Baens, M. (1992) Medicine, illness and creativity. Journal of the South Carolina Medical Association, 88, 307-317.

Bennet, G. (1987) The Wound and the Doctor. London: Secker and Warberg.

Branch, W. T., Arky, R. A., Woo, B., et al (1991) Teaching medicine as a human experience: a patient-doctor relationship course for faculty and first-year medical students. Annals of Internal Medicine, 114, 482-489.

British Medical Association (1992) Stress and the Medical Profession. London: BMA.

Burisch, M. (1993) In search of a theory: some ruminations on the nature and etiology of burn-out. In Professional Burn-out: Recent Developments in Theory and Research (eds W. B. Schaufeli, C. Maslach \& T. Marek), pp. 75-93. London: Taylor and Francis.

Burke, R. J \& Richardsen, A. M. (1996) Stress, burn-out and health. In Handbook of Stress, Medicine and Health (ed. C. Cooper), pp. 101-117. London: CRC Press.

Caplan, C. (1981) Mastery of stress: psychosocial aspects. American Journal of Psychiatry, 138, 413-420.

Caplan, R. P. (1994) Stress, anxiety, and depression in hospital consultants, general practitioners, and senior health service managers. British Medical Journal, 309, 1261-1263.

Chambers R. (1993) Avoiding burn-out in general practice. British Journal of General Practice, 43, 442-223.

- (1995) Give yourself a simple stress check up. Financial Pulse, 22nd June, 40-41.

Cherniss, C.(1993) The role of professional self efficacy in the etiology and amelioration of burn-out. In Professional BurnOut: Recent Developments in Theory and Research (ed. W. B. Schaufeli, C. Maslach \& T. Marek), pp. 135-149. London: Taylor and Francis.

Donaldson, L. (1994) Sick doctors: a responsibility to act. British Medical Journal, 309, 557-558.

Duxbury, M. L., Armstrong, G. D., Drew, D. J., et al (1984) Head nurse leadership style with staff nurse burn-out and job satisfaction in neonatal intensive care units. Nursing Research, 33, 97-101.

Edelwich, J. \& Brodsky, A. (1980) Burn-out: Stages of Disillusionment in the Helping Profession. New York: Human Sciences Press.

Fawzy, F.I., Wellisch, D. K., Pasnau, R. O., et al (1983) Preventing nursing burn-out: a challenge for liaison psychiatry. General Hospital Psychiatry, 5, 141-149.

Firth-Cozens, J. (1994) Stress in doctors: not so simple solutions. British Journal of Hospital Medicine, 52, 435-436.

Freudenberger, H. J. (1974) Staff burn-out. Journal of Social Issues, 30, 159-166.

Grainger, C. (1994) Stress Survival Guide. London: BMJ Publishing.

Guze, S. B. (1979) Can the practice of medicine be fun for a lifetime? Journal of the American Medical Association, 241, 20212023.

Halslam, D. (1994) Not Another Guide to Stress in General Practice. Sandwich: Pfizer.

Hobfoll, S. E. \& Freedy, J. (1993) Conservation of resources: a general stress theory applied to burn-out. In Professional Burnout: Recent Developments in Theory and Research (ed. W. B. Schaufeli, C. Maslach \& T. Marek), pp. 115-129. London: Taylor and Francis.

Humphris, G., Kany, S., Broomfield, D., et al (1994) Stress in Junior Hospital Medical and Dental Staff. Liverpool: University of Liverpool.

Hospital Doctor (1995) Acting to stem tide of doctor dropouts. Hospital Doctor, 18 May.

King, M. (1993) Stress Management in General Practice (Occasional Paper, OP61). London: Royal College of General Practitioners.

King, M. B., Cockcroft, A. \& Gooch, C. (1992) Emotional distress in doctors: sources, effects and help sought. Journal of the Royal Society of Medicine, 85, 605-608. 
Kirkcaldy, B. D. \& Siefen, G. (1991) Occupational stress among mental health professionals: the relationship between work and recreational pursuits. Social Psychiatry and Psychiatric Epidemiology, 26, 238-244.

MacDonald, E. B. \& McCloy, E. C. (1994) Existing services need to be coordinated (letter). British Medical Journal, 309, 1235.

Malan, D. H. (1979) Individual Psychotherapy and the Science of Psychodynamics. London: Butterworth.

Maslach, C. \& Jackson, S. E. (1986) The Maslach Burn-Out Inventory Manual (2nd edn). Palo Alto, CA: Consulting Psychologists Press.

Meier, S. T. (1983) Toward a theory of burn-out. Human Relations, 36, 899-910.

Morrow, L. (1981) The burn-out of almost everyone. Time Magazine, 21 September, 60.

Nouwen, H. J. J. M. (1994) The Wounded Healer. London: Dartman, Longman and Todd.

Pines, A. (1993) Burn-out an existential perspective. In Professional Burn-out: Recent Developments in Theory and Research (eds W. B. Schaufeli, C. Maslach \& T. Marek), pp. 35-51. London: Taylor and Francis.

-, Aronson, E. \& Kaffre, D. (1981) Burn-Out: From Tedium to Personal Growth. New York: Free Press.

— \& Maslach, C. (1978) Characteristics of staff burn-out in mental health settings. Hospital and Community Psychiatry, 29, 233-237.

Policy Studies Institute (1994) Doctors and their Careers - A New Generation. London: PSI.

Quick, J. D., Nelson, D. L., Matuszek, P. A. C., et al (1996) Social support, secure attachments, and health. In Handbook of Stress, Medicine and Health (ed. C. Cooper), pp. 269-287. London: CRC Press.

Richman, J. A. \& Flaherty, J. A. (1985) Stress, coping resources and psychiatric disorders: alternative paradigms from a life cycle perspective. Comprehensive Psychiatry, 26, 456-465.

Richards, C. (1989) The Health of Doctors (Project paper no. 78). London: King Edward's Hospital Fund for London.

Schwab, J. J. (1995) How to avoid burn-out in medical practice. KMA Journal, 93, 23-27.

Schwartz, M. S. \& Will, G. T. (1953) Low morale and mutual withdrawal on a mental hospital ward. Psychiatry, 16, 337-353.

Selye, H. (1956) The Stress of Life. New York: McGraw Hill.

Spitzer, W. J. \& Burke, L. (1993) A critical-incident stress debriefing program for hospital-based health care personnel. Health and Social Work, 18, 149-156.

Vincent, M. O. (1983) Some sequelae of stress in physicians. Psychiatric Journal of the University of Ottawa, 8, 120-128.

\section{Multiple choice questions}

1. Burn-out is:
a an imprecise metaphor
b associated with heavy smoking
c a sign of personal weakness
d a pathology of professionalism.

2. Established instruments for measuring burn-out include:
a the Tedium Scale
b personal conductivity monitoring
c the Maslach Burn-Out Inventory
d carbon dating.

3. Burn-out has been linked with:
a phase three of Selye's general stress response
b learned helplessness
c Burkowitz's thermonuclear conundrum
$\mathrm{d}$ the helping profession syndrome.

4. Signs and symptoms of burn-out can be divided into clusters centring on:
a emotional exhaustion
b excessive interest in insulative materials
c depersonalisation
d reduced personal accomplishment.

5. Burn-out is associated with those who are:
a overcommitted
b thwarted
c idealistic enthusiasts
$\mathrm{d}$ living in a small world.

6. Prevention depends on:
a avoidance
b recognition
c taking responsibility
d blaming others.

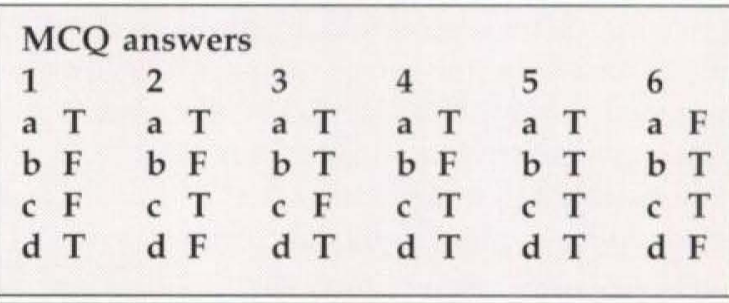

